\title{
Two new species of Protogyrodactylus (Monogenoidea: Dactylogyridae) from the gills of Gerres nigri (Teleostei: Gerreidae) from Senegal
}

\author{
Walter A. Boeger ${ }^{1}$, Arfang Diamanka ${ }^{2}$, Antoine Pariselle ${ }^{3}$ and Luciana Patella ${ }^{1}$ \\ ${ }^{1}$ Molecular Ecology, Evolutionary Parasitology Laboratory, Departamento de Zoologia and Grupo Integrado de Aquicultura \\ e Estudos Ambientais, Caixa Postal 19073, Universidade Federal do Paraná, Brazil; \\ ${ }^{2}$ Laboratory of Parasitology and Laboratory of Aquatic Animals Pathologies - Khaled Bin Sultan Living Oceans Foundation, \\ Department of Animal Biology, Faculty of Sciences and Technologies, University Cheikh Anta Diop, Dakar, Senegal; \\ ${ }^{3}$ UR 203 / UMR 5554, IRD/ISE-M, Université Montpellier II - CC 063, 34095 Montpellier Cedex 5, France
}

\begin{abstract}
Protogyrodactylus ethiopicus sp. n. and P. kritskyi sp. n. are described from the gills of Gerres nigri Günther (Gerreidae, Perciformes) captured from the estuary of the Sine-Saloum River (Senegal, West Africa). These new species differ from previously described species within the genus by a mid- or dextro-ventral vaginal opening (dextral in all other species). They are part of a morphological species group within Protogyrodactylus Johnston et Tiegs, 1922 that has the tip of the superficial root of the ventral anchor resembling a hook and two anterior projections on the anterior margin of the ventral bar. Protogyrodactylus ethiopicus differs from the remaining species in this group mainly by the morphology of the base of the male copulatory organ (MCO), which is disk-shaped, and the shape of the anterior projections of the ventral bar (round in the new species and relatively elongate in the other species of the group). The other new species, $P$. kritskyi, differs from all others in the same morphological group in having a MCO with a greatly expanded base that bears a heel-like subterminal sclerotization.
\end{abstract}

Keywords: Protogyrodactylus, Gerres nigri, Senegal, Protogyrodactylus ethiopicus, Protogyrodactylus kritskyi

Protogyrodactylus Johnston et Tiegs, 1922 (Monogenoidea: Ancyrocephalinae) comprises approximately 25 species that parasitize the gills of fishes of the Terapontidae and Gerreidae (see Galli and Kritsky 2008) from oceans of the eastern hemisphere. The taxonomic history of Protogyrodactylus is relatively complex, likely associated with inaccurate descriptions of the first species included in the genus (see Galli and Kritsky 2008 for a detailed history of the taxon). Species of Protogyrodactylus, however, share a unique combination of characters that makes the recognition of species of the genus simple: copulatory complex comprising a clockwise coiled tube with bulbous base; accessory sclerite associated with the tip of the superficial root of the ventral anchor; dorsal anchor with elongate superficial root usually with small distal hook-like extension, knob-like deep root, slightly curved shaft and recurved point; ventral bar rod-shaped, usually with two variable anteromedial projections; and two dorsal bars, each medially spatulated. Most taxonomic problems associated with Protogyrodactylus are likely due to the relatively small size of its species, some reaching less than $250 \mu \mathrm{m}$ in length, making study of their morphology slightly more complicated than in species of other taxa.

In this study, specimens of Gerres nigri Günther captured along the coast of Senegal, eastern Atlantic Ocean, were parasitized by two new species of Protogyrodactylus. These species are described and illustrated herein.

\section{MATERIALS AND METHODS}

During an ecological survey in the Marine Protected Area of the estuary of the Sine-Saloum River, Senegal, West Africa, from 2006 to 2009, 121 specimens of G. nigri were captured by purse seine and dissected immediately or frozen until examination. Gills of each fish were removed, placed into vials containing local water, and vigorously shaken and fixed in $3-5 \%$ formalin. In the laboratory, monogenoids were removed from the sediment using a small probe and a dissecting microscope. Some specimens were stained with Gomori's trichrome and mounted in Canada balsam for study of their soft anatomy; other specimens were cleared and mounted in Hoyer's or Gray and Wess' media for study of their sclerotized structures (all solutions prepared as in Humason 1979). Illustrations were

Address for correspondence: W.A. Boeger, Molecular Ecology, Evolutionary Parasitology Laboratory, Departamento de Zoologia, Caixa Postal 19073, Universidade Federal do Paraná, Brazil. Phone/Fax: 55-41-33611765; E-mail: wboeger@gmail.com 
prepared with the aid of a camera lucida on an Olympus BX51 microscope equipped with phase contrast. Measurements, all in micrometres, were made following the procedures of Mizelle and Klucka (1953); the mean is followed by the range and the number of structures measured (n) in parentheses; body length includes that of the haptor (longitudinal axis of haptor added to that of body proper); and the width of the germarium is that of its bulbous portion. Numbering of the hook pairs follows that recommended by Mizelle (1936) and Mizelle and Price (1963). Type specimens are deposited in the Helminthological collection of the Muséum National d'Histoire Naturelle (MNHN), Paris, France; the United States National Parasite Collection (USNPC), Beltsville, USA; and the Coleção Helmintológica do Instituto Oswaldo Cruz, Rio de Janeiro, Brazil (CHIOC) as indicated in the respective descriptions.

\section{RESULTS}

Dactylogyridae Bychowsky, 1933

Protogyrodactylus ethiopicus sp. n.

Figs. 1-7, 14, 16, 17

Description (based on 37 specimens): Body 259 (188-309; $\mathrm{n}=13$ ) long, fusiform; greatest width 72 $(58-82 ; \mathrm{n}=13)$ at level of gonads. Tegumental scales of variable shape present from haptor to pharyngeal region. Cephalic lobes moderately to poorly developed; each lobe with 2-3 head organs. One pair of eyespots; accessory granules sparse or absent in cephalic region. Pharynx sub-spherical, $23(20-27 ; \mathrm{n}=11)$ wide. Testis sub-spherical, 36 (28-46; $n=7)$ long, 34 (23-43; $n=7)$ wide; vas deferens looping left intestinal caecum; seminal vesicle not observed; prostatic reservoir fusiform. Copu-

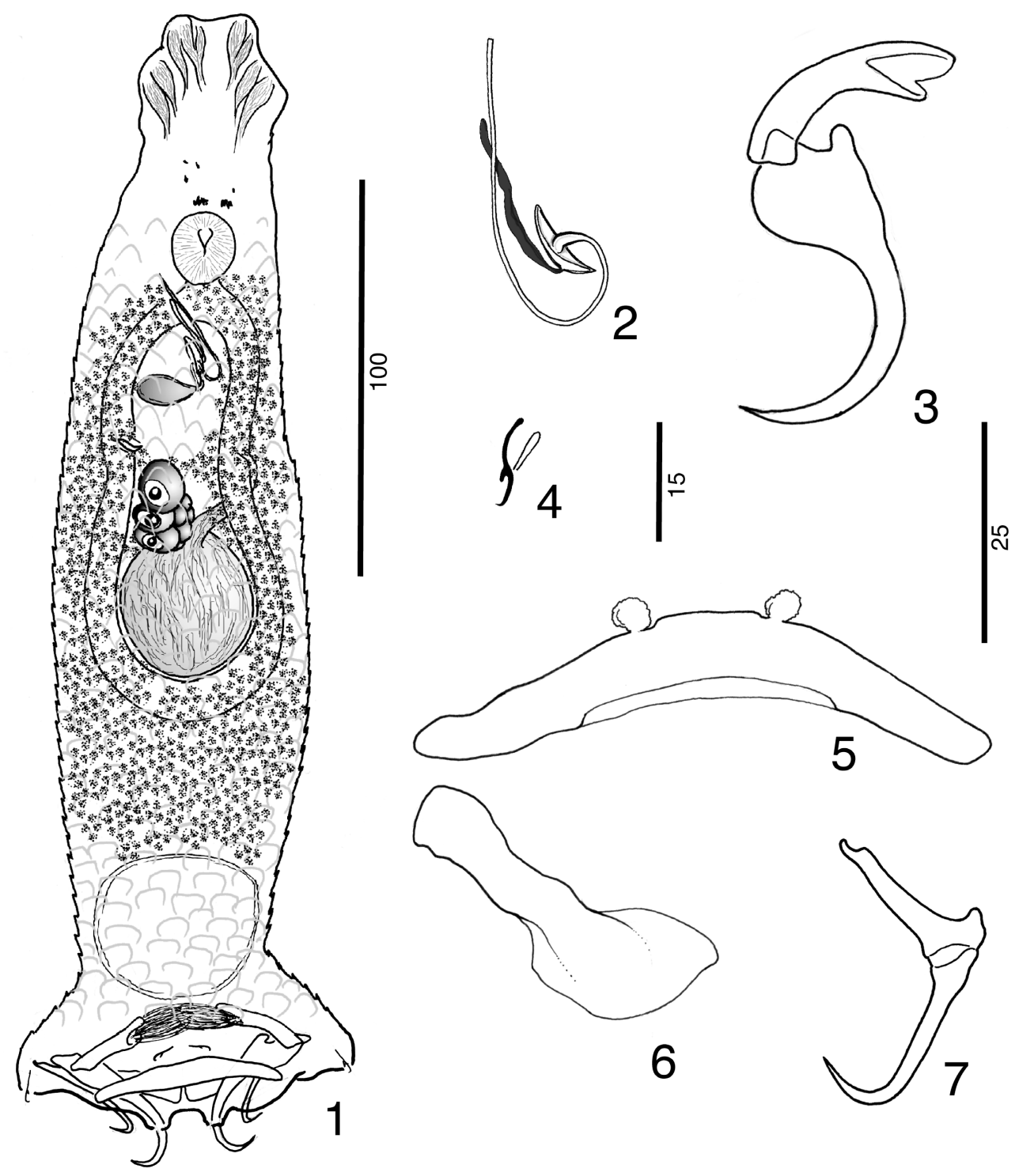

Figs. 1-7. Protogyrodactylus ethiopicus sp. n. Fig. 1. Holotype (ventral view). Fig. 2. Male copulatory organ. Fig. 3. Ventral anchor and accessory sclerite complex. Fig. 4. Hook. Fig. 5. Ventral bar. Fig. 6. Member of the pair of dorsal bars. Fig. 7. Dorsal anchor. Scale bars: $2,3,5-7=25 \mu \mathrm{m}$. 
latory complex composed by articulated male copulatory organ (MCO) and accessory piece; MCO 43 (29-57; $\mathrm{n}=14$ ) long, an incomplete spiral; base of MCO slightly bulbous with large disk-shaped flange; accessory piece single, unbranched. Germarium $33(27-37 ; \mathrm{n}=8)$ long, 25 (19-30; $\mathrm{n}=8)$ wide; uterus inconspicuous; vaginal pore ventral to right intestinal caecum; vagina apparently non-sclerotized, inconspicuous; vitellaria dense. Peduncle containing apparent reservoir of haptoral secretions (Fig. 1). Haptor 39 (33-46; $\mathrm{n}=13$ ) long, 89 (81-100; $\mathrm{n}=11$ ) wide, bilaterally expanded. Hooks 7 pairs, with ancyrocephaline distribution, $12(9-16 ; n=60)$, similar in shape, with erect thumb, evenly curved point and shaft, short shank. Ventral anchor $41(36-45 ; n=15)$ long, robust, with expanded base, short roots, evenly curved shaft and point; ventral anchor sclerite $35(29-48 ; \mathrm{n}=16)$ long, robust, terminally indented and concave. Dorsal anchor $34(27-40 ; n=14)$ long, delicate, with short deep root, elongate superficial root with terminal hook, hinge-line located between base and shaft, elongate straight point, strongly recurved point; base and shaft often positioned at about 90 degrees from each other. Ventral bar 68 (58-82; $\mathrm{n}=16$ ) long, with slightly tapering ends; antero-bilateral projections (muscle attachments). Dorsal bars 30 (20-43; $\mathrm{n}=7$ ) long, with thin spatulate medial end.

Type host: Gerres nigri Günther (Gerreidae, Perciformes). Site of infection: Gills.

Type locality: Bamboung, Sine-Saloum River, Senegal $\left(13^{\circ} 49^{\prime} 30.5^{\prime \prime} \mathrm{N}, 16^{\circ} 31^{\prime} 44^{\prime \prime} \mathrm{W}\right)$; collections between May 2006 and October 2009.

Prevalence: $98 \%$ (119 infected / 121 fish examined).

Specimens deposited: Holotype No. MNHN HEL222.

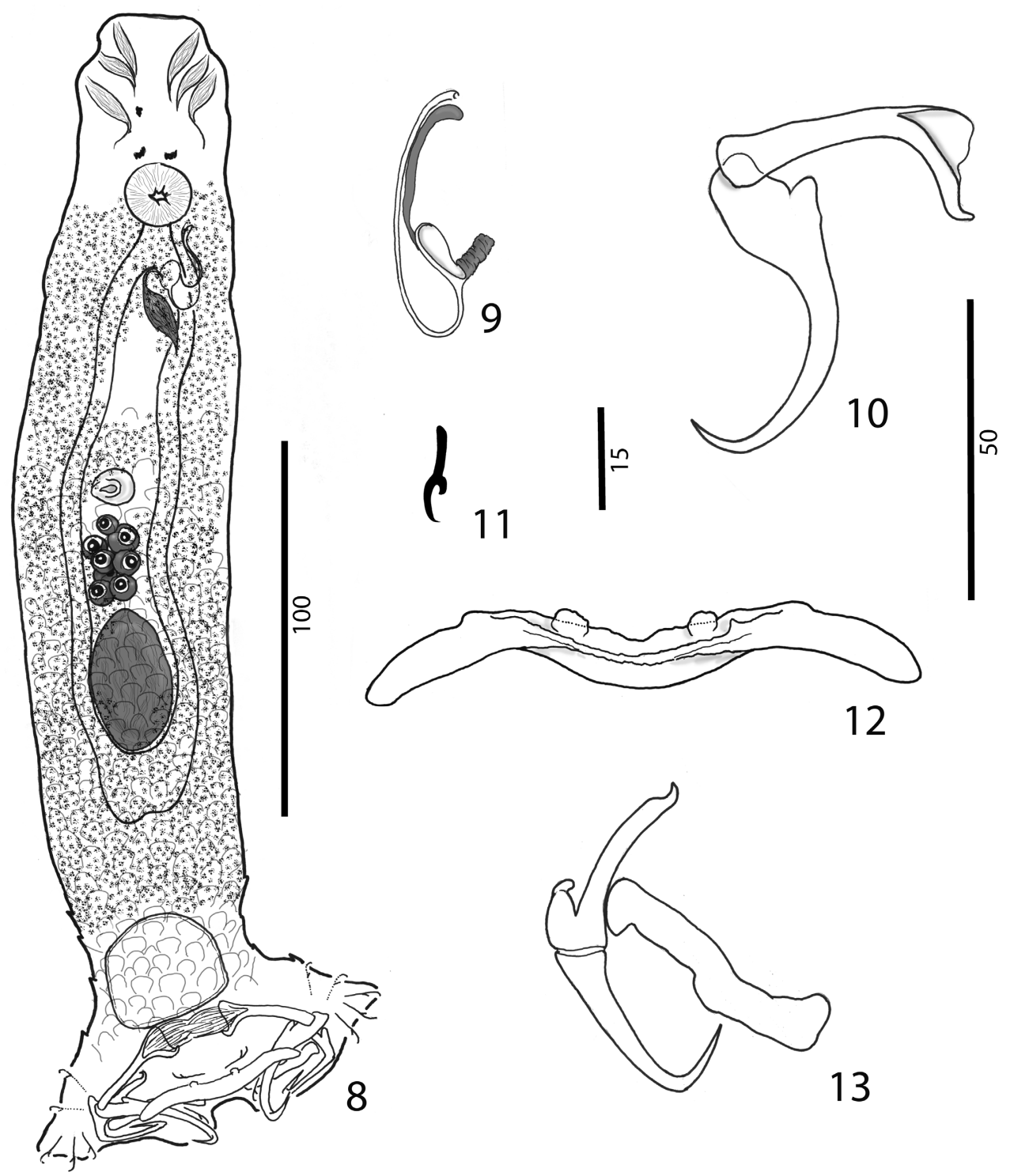

Figs. 8-13. Protogyrodactylus kritskyi sp. n. Fig. 8. Holotype (ventral view). Fig. 9. Male copulatory organ. Fig. 10. Ventral anchor and accessory sclerite complex. Fig. 11. Hook. Fig. 12. Ventral bar. Fig. 13. Dorsal anchor and member of the pair of dorsal bars. Scale bars: $9,10,12,13=50 \mu \mathrm{m}$. 

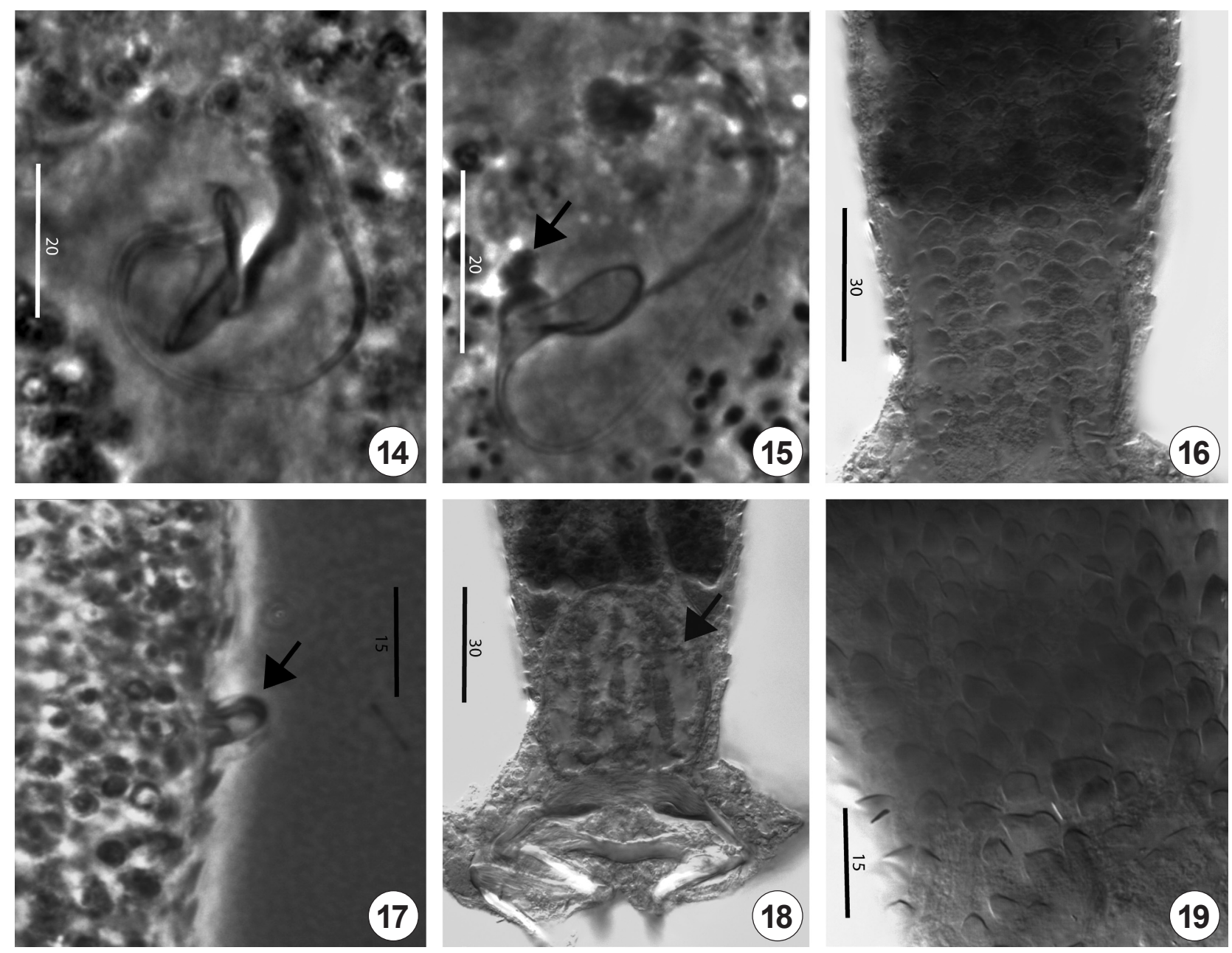

Figs. 14-19. Protogyrodactylus ethiopicus sp. n. and P. kritskyi sp. n.; phase contrast micrographs. Fig. 14. Copulatory complex of P. ethiopicus. Fig. 15. Copulatory complex of $P$. kritskyi. Arrow indicates the heel-like sclerotization of the base of the male copulatory organ. Fig. 16. Tegumental scales on the peduncular region of $P$. ethiopicus. Fig. 17. Vaginal opening of P. ethiopicus (arrow). Fig. 18. Peduncular reservoir of $P$. kritskyi (arrow). Fig. 19. Tegumental scales on the peduncular region of $P$. kritskyi.

Paratypes: MNHN HEL223 to HEL 235 ( $\mathrm{n}=13)$; USNPC 105078 to $105079(\mathrm{n}=10)$; CHIOC $37744 \mathrm{a}-\mathrm{n}(\mathrm{n}=14)$.

Etymology: The specific name is derived from the Ethiopian Biogeographic Realm, from which the species was collected.

Remarks. Protogyrodactylus ethiopicus is a member of the morphological species group of the genus that has the tip of the superficial root of the ventral anchor resembling a hook. All members of this group are parasites of Gerres spp. (Gerreidae). Within this species group, some are likely closer to the new species by sharing two anterior projections on the margin of the ventral bar (Protogyrodactylus pricei Venkatanarasaiah, 1982; P. alatus Galli et Kritsky, 2008; P. federicae Galli et Kritsky, 2008). The new species, however, can be easily differentiated from all species of this group by the morphology of the MCO base, which is disk-shaped, and the shape of the anterior projections of the ventral bar (round in the new species and relatively elongate in the other species of the group).
Additional differences among these species are conspicuous on the comparative morphology of the remaining haptoral sclerites, in special of the ventral and dorsal anchors.

\section{Protogyrodactylus kritskyi sp. n.}

Figs. 8-13, 15, 18, 19

Description (based on 8 specimens). Body 282 (205$329 ; \mathrm{n}=15)$ long, fusiform; greatest width 82 (61-95; $\mathrm{n}=16$ ) at level of gonads. Tegumental scales of variable shape present from haptor to body midlength. Cephalic lobes moderately to poorly developed; each lobe with 1-2 head organs. One pair of eyespots; anterior eyespots present or accessory granules sparse or absent in cephalic region. Pharynx sub-spherical, $28(20-34 ; \mathrm{n}=17)$ wide. Testis sub-spherical, $44(30-54 ; \mathrm{n}=14)$ long, 37 (24-48; $\mathrm{n}=14$ ) wide; vas deferens not observed; seminal vesicle fusiform; prostatic reservoirs not observed. Copulatory complex articulated; MCO $48(43-57 ; \mathrm{n}=6)$ long, J-shaped; base of MCO large, labiate with a sclerotized, 
elongate, subterminal projection (Figs. 9, 15). Germarium $32(27-36 ; n=13)$ long, $26(17-36 ; n=13)$ wide; uterus inconspicuous; vaginal pore near body mid-length, anterior to germarium; vagina apparently non-sclerotized, inconspicuous, ventral; vitellaria dense. Haptor 52 (38$87 ; \mathrm{n}=17)$ long, $102(75-124 ; \mathrm{n}=17)$ wide; bilaterally expanded. Hooks 7, with ancyrocephaline distribution, $13(11-15 ; n=28)$ long, similar in shape and size, with erected thumb, evenly curved point and shaft, short robust shank. Ventral anchor $49(46-53 ; n=8)$ long, with short deep root, robust superficial root, slightly curved shaft, recurved point; ventral anchor sclerite $47(43-51 ; n=10)$ long, delicate, terminally wide, strongly indented, concave. Dorsal anchor $46(42-57 ; n=9)$ long, delicate, with short deep root, elongate superficial root with terminal hook, hinge-area located between base and shaft (often positioned at $90^{\circ}$ from each other), elongate straight shaft, strongly recurved point. Ventral bar $95(86-110 ; n=11)$ long, with antero-bilateral projections (muscle attachments) and longitudinal ridge in its medium third. Dorsal bars $43(30-50 ; \mathrm{n}=10)$ long, with slightly expanded medial end.

Type host: Gerres nigri Günther (Gerreidae, Perciformes). Site of infection: Gills.

Type locality: Bamboung, Sine-Saloum River, Senegal $\left(13^{\circ} 49^{\prime} 30.5^{\prime \prime} \mathrm{N}, 16^{\circ} 31^{\prime} 44^{\prime \prime} \mathrm{W}\right)$; collection made in May 2006.

Prevalence : $59 \%$ (71 infected / 121 fish examined).

S pecimens deposited: Holotype No. MNHN HEL208. Paratypes: MNHN HEL209 to HEL221 $(\mathrm{n}=13)$; USNPC 105077 ( $\mathrm{n}=13)$; CHIOC $37743 \mathrm{a}-\mathrm{k}(\mathrm{n}=11)$.

Ety mology: The specific epithet was chosen in honour to Dr. Delane C. Kritsky (Idaho State University, USA) for his impressive contributions on the taxonomy of fresh water and marine Monogenoidea.

Remarks. Protogyrodactylus kritskyi is also a member of the species group from the gills of Gerres spp. that has the tip of the dorsal anchor resembling a hook. The new species closely resembles $P$. ethiopicus by the presence of two round projections on the anterior margin of the ventral bar. Differentiation of these two species is, however, relatively simple. Protogyrodactylus kritskyi has a distinct morphology of the MCO, with a greatly expanded base that bears a heel-like subterminal sclerotization (Figs. 9 and 15). Further, the hook of P. kritskyi is more robust and the ventral anchor more delicate, with a recurved point (P. ethiopicus has an evenly curved shaft and point).

\section{DISCUSSION}

The two new parasites described here raise to 13 the number of species of Protogyrodactylus recorded from Gerreidae: P. scapulasser (Mamaev, 1970) Gussev, 1973 (syn. Ancyrocephalus scapulasser Mamaev, 1970); P. alienus Bychowsky et Nagibina, 1974; P. delicatus Bychowsky et Nagibina, 1974; P. elegantis Bychowsky et Nagibina, 1974; P. fissilis Bychowsky et Nagibina, 1974; P. sprostonae Bychowsky and Nagibina, 1974; P. youngi Bychowsky et Nagibina, 1974; P. pricei, P. alatus, P. federicae, and P. zullinii Galli et Kritsky, 2008. Protogyrodactylus ethiopicus and $P$. kritskyi appear to be host specific. Another gerreid, Eucinostomus melanopterus (Bleeker), occurs in the same area (the Sine-Saloum Estuary, Casamance, and other rivers in Senegal) and has been extensively examined for ectoparasites. However, this host species is not infected by any species of Protogyrodactylus but harbours a species of Diplectanidae (see Domingues et al. 2011). This is the first record of Protogyrodactylus in Senegal. The ongoing examination of species of Gerreidae by one of us (AD) in the same area will likely uncover additional described and undescribed species of monogenoids. Although the Gerreidae includes about 50 valid species (Froese and Pauly 2011), only 7 are known to host species of Protogyrodactylus.

\section{REFERENCES}

Domingues M.V., Diamanka A., Pariselle A. 2011: Monogenoids (Diplectanidae, Polyonchoinea) from the gills of mojarras (Perciformes, Gerreidae) with the resurrection of Neodiplectanum Mizelle and Blatz, 1941 and the proposal of Darwinoplectanum n. gen. Zootaxa 3010: 1-19.

Froese R., Pauly D. (Eds.) 2007: FishBase. World Wide Web electronic publication. www.fishbase.org, version 08/2011.

Galli P., Kritsky D.C. 2008: Three new species of Protogyrodactylus Johnston and Tiegs, 1922 (Monogenoidea: Dactylogyridae) from the gills of the longtail silverbiddy Gerres longi-

Received 16 September 2011 rostris (Teleostei: Gerreidae) in the Red Sea. Syst. Parasitol. 69: 221-231.

Humason G.L. 1979: Animal Tissue Techniques. 4th ed. W.H. Freeman and Co. (Sd). 468 pp.

Mizelle J.D. 1936: New species of trematodes from the gills of Illinois fishes. Am. Midl. Nat. 17: 785-806.

Mizelle J.D., Klucka A.R. 1953: Studies on monogenetic trematodes. XIV. Dactylogyridae from Wisconsin fishes. Am. Midl. Nat. 49: 720-733.

Mizelle J.D., Price C.E. 1963: Additional haptoral hooks in the genus Dactylogyrus. J. Parasitol. 49: 1028-1029.

Accepted 22 November 2011 